\title{
Correction to: Mental Health in Immigrant Children and Adolescents in Northern Chile
}

\author{
Alejandra Caqueo-Urízar ${ }^{1} \cdot$ Diego Atencio $^{2} \cdot$ Jerome Flores $^{2} \cdot$ Marigen Narea $^{3} \cdot$ Alfonso Urzúa $^{4} \cdot$ Matías Irarrázaval $^{5}$
}

Published online: 24 October 2020

○) Springer Science+Business Media, LLC, part of Springer Nature 2020

\section{Correction to: Journal of Immigrant and Minority Health https://doi.org/10.1007/s10903-020-01101-7}

The original version of this article unfortunately contained an error in article title.

The part of article title was repeated inadvertently. Hence, the article was published with incorrect title "Mental Health in Immigrant Children and Adolescents in Northern Chile Mental Health in Immigrant Children and Adolescents"
Therefore, the correct title is "Mental Health in Immigrant Children and Adolescents in Northern Chile"

Publisher's Note Springer Nature remains neutral with regard to jurisdictional claims in published maps and institutional affiliations.

The original article can be found online at https://doi.org/10.1007/ s10903-020-01101-7.

Alejandra Caqueo-Urízar

acaqueo@academicos.uta.cl

1 Instituto de Alta Investigación, Universidad de Tarapacá, Antofagasta 1520, Arica, Chile

2 Escuela de Psicología y Filosofía and Centro de Justicia Educacional, CJE, Universidad de Tarapacá, Arica, Chile

3 Escuela de Psicología and Centro de Justicia Educacional, CJE, Pontificia Universidad Católica de Chile, Santiago, Chile

4 Escuela de Psicología, Universidad Católica del Norte, Antofagasta, Chile

5 Departamento de Psiquiatría, Facultad de Medicina, Hospital Clínico, Universidad de Chile, Santiago, Chile 